\title{
A Case Study of Auditory Training for an Adult with Sudden Sensorineural Hearing Loss
}

\author{
Selim Cho ${ }^{1,2}$, Soo Hee Oh³, Junghwa Bahng' \\ 'Department of Audiology, Hallym University of Graduate Studies, Seoul, Korea \\ ${ }^{2}$ Siemens Hearing Center, Anyang, Korea \\ ${ }^{3}$ Hallym Hearing and Speech Institute, Hallym University of Graduate Studies, Seoul, Korea
}

\section{돌발성 난청 성인의 청능훈련 사례}

조새림 ${ }^{12} \cdot$ 오수희 ${ }^{3} \cdot$ 방정화 $^{1}$

한림국제대학원대학교 청각학과 ${ }^{1}$, 지멘스보청기 안양센터 ${ }^{2}$, 한림국제대학원대학교 청각언어연구소 ${ }^{3}$

\begin{abstract}
Purpose: A 43-year-old woman diagnosed with a sudden sensorineural hearing loss. She did not accept her hearing loss and did not want to wear hearing aids, but her communication ability was the problem in her workplace. The purpose of this study was to investigate the efficacy of auditory training for improving communication ability through listening activities, and for accepting her hearing loss and wearing a hearing aid continuously through informational counseling. Methods: Receiver in canal hearing aid was selected for the left ear. Auditory training was conducted seven sessions for 30 mins listening activities and 10 minutes informational counseling. For listening activities, long stories were used, and for informational counseling, effects of hearing loss on communication, knowledge of hearing aids and emotional well-being were provided. Also, we simulated her workplace for training sessions. As objective assessments, word and sentence recognition scores were tested and as a subjective assessment, Korean Version of Profile Hearing Aid Benefit (K-PHAB) was conducted. Results: The recognition scores of word and sentence were improved after the auditory training. However, scores of KPHAB were not changed. The subject reported that she did not feel that her communication ability did not improve a lot, but she would maintain to use her hearing aid. Conclusion: Even though the subjective hearing aid benefit was not improved, behaviors of the subject were changed after the auditory training. Informational counseling is efficacy to understand and accept hearing loss and hearing aids.
\end{abstract}

Key Words: Sudden sensorineural hearing loss, Auditory training, Counseling.

Received: October 3, 2017 / Revised: January 8, 2018 / Accepted: January 9, 2018

Correspondence: Junghwa Bahng, Department of Audiology, Hallym University of Graduate Study, 405 Yeoksam-ro, Gangnam-gu, Seoul 06198, Korea Tel: +82-70-8680-6933 / Fax: +82-2-3451-6618 / E-mail: bahng.jh@gmail.com

\section{INTRODUCTION}

돌발성 난청(sudden sensorineural hearing loss)은 72시간 이내에 편측 또는 양측 귀에 발생한 갑작스런 청력손실로, 최소 3 개 이상의 연속적인 주파수에서 $30 \mathrm{~dB} \mathrm{HL}$ 이상의 청력손실 이 발생된 경우를 진단 기준으로 한다(Schreiber et al., 2010; Stachler et al., 2012). 인구 100,000명당 약 5 30명(Stachler et al., 2012; Wu et al., 2006)의 발생률을 보이며 국내 돌발성 난 청 발생률은 100,000명당 10명 이상으로(Korean Audiological Society, 2017), 건강보험심사평가원(Health Insurance Review and Assessment Service, 2017)은 2011년 돌발성 난청 환자수 가 55,437명에서 2015년 71,411명으로 29\% 증가하였고, 2016년
에는 75,937 명으로 5 년간 연평균 약 $6 \%$ 씩 증가하는 것으로 보 고하였다. 주로 혈관장애, 바이러스성 감염, 자가면역성 질환 등 이 대표적 원인으로 추측되나 정확한 발병 원인을 파악하기 어 려운 경우가 많고 이로 인해 특발 돌발성 난청(idiopathic sudden sensorineural hearing loss)으로 부르기도 한다(Schreiber et al., 2010; Stachler et al., 2012). 일반적으로 코티코스테로이 드(corticostreoid) 투여 및 필요한 다른 처치를 병행하여 치료하 고 가장 효과적인 치료방법에 대해서는 아직까지 논란의 여지가 있다(Schreiber et al., 2010; Sekiya et al., 2016; Stachler et al., 2012). 한 예로 Sekiya et al.(2016)은 최근 "constraint-induced sound therapy"를 소개하고 헤드폰의 음악자극을 코티코스테 로이드와 함께 병행했을 때 돌발성 난청 환자의 청력회복 및 재 
활에 긍정적 효과가 있음을 보고한 바 있다. 일반적으로 돌발성 난청의 약 $2 / 3$ 는 발병 전 청력을 완전 또는 부분적으로 회복하 고 $1 / 3$ 은 청력을 완전히 회복하지 못하는 것으로 보고되었으며 (Korean Audiological Society, 2017; Stachler et al., 2012), 의 과적 치료로 청력이 회복되지 못하고 난청이 발생한 경우 보청 기나 인공와우 등 적절한 청각기기를 사용하여 중재하고 재활 중심의 사후관리를 시행한다(Stachler et al., 2012). 이에 돌발 성 난청인의 개별적 특징을 고려한 청능재활은 돌발성 난청으 로 인한 보청기나 인공와우 사용자의 사후관리에 도움이 될 수 있을 것이다.

청능훈련은 사용자의 청각적 능력을 극대화하고 의사소통을 향상시키는 데 그 목적이 있으며 주로 반복적이고 집중적인 듣 기 활동으로 구성된다. 성인의 경우 청각기기 적합 후 매주 1 2 회씩 총 10 15회 정도 시행하고 각 회기마다 듣기훈련과 상담 을 포함하며 그 효과는 이미 여러 연구에서 보고하였다(Kim \& Bahng, 2017; Lee et al., 2017; Lee et al., 2016). 특히 청능훈련 은 훈련을 담당하는 청각 관련 전문가와의 주기적 상담과 상호 관계를 통해 청력손실로 인해 발생하는 개인의 의사소통 및 부 수적 어려움을 파악하는 것은 물론 이에 대한 해결 방안을 심도 있게 모색할 수 있다는 점에서 그 장점이 있다(Sweetow \& Sabes, 2010).

돌발적 청각손실로 인한 난청인은 갑작스러운 청력저하로 심 리적 충격을 많이 받을 수 있는데, Clark \& English(2014)에 의 하면 진행성 난청에 비해 돌발성 난청은 시간 경과에 따른 난청 의 향상을 기대하면서 자신의 난청을 수용하기까지 지속적인 심적 어려움을 겪는 것으로 보고하였다. 이와 관련하여 돌발성 난청이 우울장애의 발병 또는 발병 위험요인과도 밀접한 관련 이 있는 것으로 보고되었다(Chen et al., 2013; Lin et al., 2016; Tseng et al., 2016). Tseng et al.(2016)은 돌발성 난청그룹은 돌 발성 난청이 없는 그룹보다 2.17배 높은 우울장애 위험요소가 있는 것으로 보고하였으며 돌발성 난청 환자의 사후관리에서 심 리적 평가 및 지원의 필요성을 언급하였다. 147 명의 돌발성 난청 인을 대상으로 한 Chen et al.(2013)의 연구에서는 생각과 감정, 활동과 개인성, 관계, 물리적 증상과 관계된 정신적 피로 정도와 돌발성 난청의 회복 사이에 의미 있는 관계가 있는 것으로 보고 하였으며, 특히 지속적 이명과 함께 돌발성 난청에서 회복되지 않은 것으로 분리된 그룹의 정신적 피로는 위의 생각과 감정, 활 동과 개인성, 관계, 물리적 증상 이외에 자살충동 요인까지 포함 된 것으로 보고되어 돌발성 난청이 회복되지 못한 경우의 심리 적 피로나 압박이 상당히 심각한 것으로 보고되었다.

이러한 우울장애 또는 정신적 피로감의 발생은 갑작스럽게 발생된 난청의 수용과 이에 대한 심리 사회적 적응의 어려움 및 스트레스와 밀접한 관련이 있을 것으로 생각된다. 난청 수용
에 어려움이 있는 경우, 청능재활 훈련을 체계적이고 효과적으 로 진행하기 어렵고 의사소통의 어려움뿐 아니라 심리 사회적으 로 가중된 여러 어려움을 겪게 된다(Tye-Murray, 2009). 그러므 로 돌발성 난청의 경우 자신의 청력 상태에 심리 사회적으로 잘 적응하고 청각기기 사용을 극대화하기 위해서 개인별 맞춤 전 략 중심의 청능훈련과 지속적 상담을 통해 장비 사용에 대한 동기부여 및 자기 효능감을 극대화하는 것이 무엇보다도 중요 할 것이다.

본 사례에서는 돌발성 난청 이후 청력이 회복되지 못한 보청기 사용자를 대상으로 청력손실이 의사소통에 미치는 영향, 보청기 에 대한 부정적 인식을 감소시키기 위하여 보청기 사용에 대한 지식 제공 그리고 정서적 불안감을 해소하기 위한 내용으로 상 담을 제공하였으며, 실질적 근무 환경을 모의한 조건하에서 보청 기 적응 및 의사소통 향상에 중점을 둔 맞춤형 청능훈련을 시행 하였다. 이러한 결과를 통하여 향후 돌발성 난청으로 인한 난청 인의 청능재활과 사후관리 체계 마련에 도움이 되고자 한다.

\section{MATERIALS AND METHODS}

\section{대상자 배경정보}

본 연구는 한림국제대학원대학교 생명윤리위원회의 승인을 받아 진행하였다(IRB \#HUGAUD 439175).

지멘스보청기센터를 방문한 43세의 여성은 우측 귀에 3 번의 돌발성 난청이 반복적으로 발병하였는데, 3 번째 돌발성 난청 시 우측 귀에 심도 난청 발생 뒤 의사소통의 어려움을 겪어왔 다. 센터 방문 당시 개인병원 간호사로 근무하고 있었으며 직장 내 의사소통의 어려움을 해결하기 위해 센터를 방문하였다. 특 히 같이 근무하는 의사와의 의사소통에 어려움이 있었으며 직 장에서 같이 일하는 데 불편함을 느낀 동료 의사의 권유로 본 센터를 방문하게 되었다. 난청의 가족력은 없었으며 외이 또는 중이와 관련된 이과적 병력 또한 없었다. 대상자는 보청기 착용 경험이 전혀 없었으나 처음 센터 방문 시부터 보청기 및 착용 효 과에 대한 심한 거부감과 부정적 태도를 보여왔다. 상담을 통해 서 대상자의 직장 근무 환경을 확인한 결과, 대상자는 큰 도로 가 인접해 있는 건물 1 층에서 근무하며 도로변에 인접한 창문 을 열어놓은 상태로 근무하여 진료실 내에서 창문을 통한 자동 차 및 외부 소음이 들릴 뿐 아니라 열어놓은 진료실 문으로 인 해 대기실의 TV 소리도 들리는 상황에서 근무하고 있음을 알 수 있었다. 이를 통해 환경소음과 반향음이 있는 환경에서 대상 자는 근무하고 있으며, 병원을 방문하는 노인 환자와 동료 의사 가 직장에서의 주요 의사소통 대상자임을 파악할 수 있었다. 


\section{청력평가}

대상자의 기도 및 골도 청력역치 레벨 및 단어인지도의 평가 는 청력검사기기 Unity 2 (Siemens Hearing Instruments, Crawley, West Sussex, UK)와 TDH-49 헤드폰(Interacoustics, Copenhagen, Denmark)을 착용한 뒤 방음실에서 시행하였다. 단 어인지도 및 문장인지도 평가는 각각 한국표준(Korean Standard, 2009)의 KS-MWL-A와 KS-S-A 단음절 목록을 사용 하였다.

순음청력검사에서 우측 $250 \mathrm{~Hz}$ 에서 $8,000 \mathrm{~Hz}$ 사이에 $80 \mathrm{~dB}$ $\mathrm{HL}$ 에서 $110 \mathrm{~dB}$ HL의 청력을 보였고 좌측도 원인을 알 수 없 는 청력손실로 $250 \mathrm{~Hz}$ 에서 $8,000 \mathrm{~Hz}$ 사이에 $25 \mathrm{~dB} \mathrm{HL}$ 에서 $60 \mathrm{~dB}$ HL 의 청력을 보였으며 양이 간 $55 \mathrm{~dB}$ HL의 평균 역치 차이를 보였다. 어음청력검사에서 단어인지도(word recognition score, WRS)는 우측 $28 \%$, 좌측 $64 \%$, 문장인지도(sentence recognition score, SRS)는 우측 $42.5 \%$, 좌측 $72.5 \%$ 의 결과를 보였다(Figure 1).

\section{보청기 선택}

양이 비대칭형 청력손실로 바이크로스(BiCROS) 형태의 보청 기 착용을 권하고 시범 착용하였으나 대상자가 양쪽에 보청기 를 착용하여야 한다는 이유로 좌측 일반 보청기를 선택하였다. 미용상 선호로 invisible-in-the-canal (IIC)형 보청기를 시도하

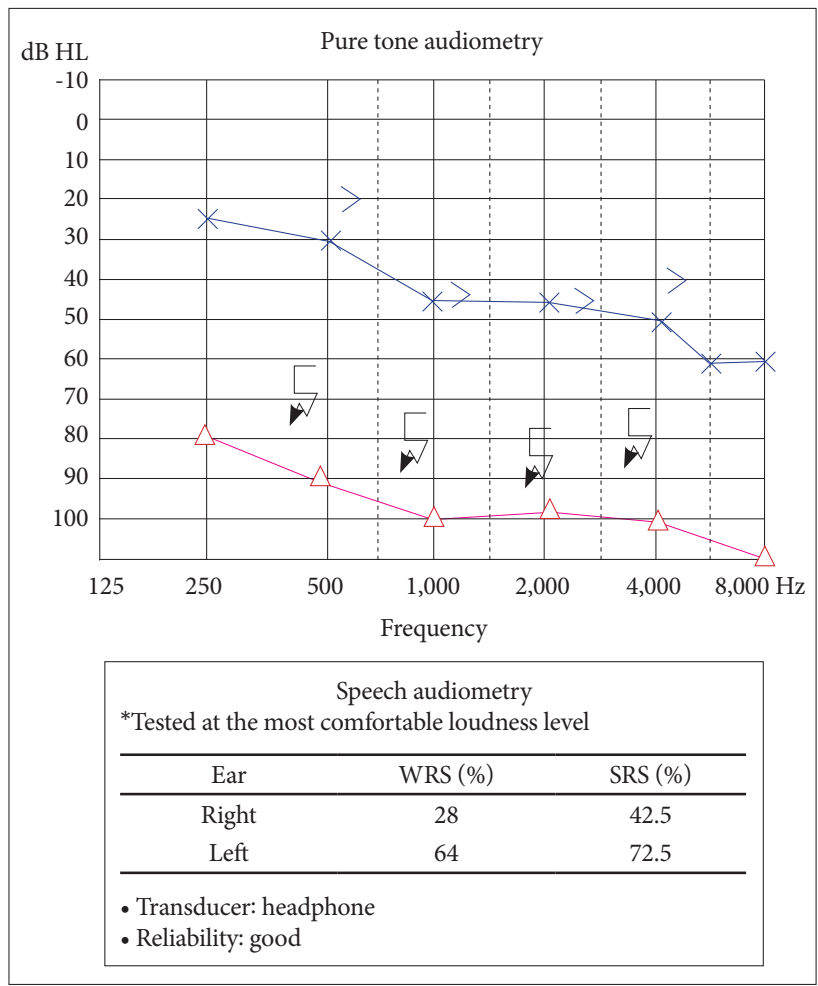

Figure 1. Results of pre-hearing aid evaluation of subjects. WRS: word recognition score, SRS: sentence recognition score.
였으나 울림 현상으로 인한 불편함으로 receiver in canal (RIC) 형 보청기로 다시 선택하였다. Table 1은 최종 선정한 대상자의 보청기 정보이다.

\section{보청기 적합}

보청기 초기 적합은 제조사(Simens Hearing Aids) 적합공식 인 binax fit으로 진행하였다. 1차 조절 시 첫 착용임을 고려하여 목표 이득의 $70 \%$ 수준으로 이득을 조절하였으며 울림 현상에 민감하다는 점을 고려하여 저주파수 이득을 비교적 낮게 설정 하였고 추가적 적합을 통해 이득을 목표이득 수준까지 점차 올 리기로 계획하였다. 2 주 후 시행한 2 차 조절에서는 보청기 착용 후 울림 현상이 사라지지 않고 말소리 분별의 개선이 느껴지지 않는다고 하여 $500 \mathrm{~Hz}$ 이하의 저주파수 이득을 $4 \mathrm{~dB}$ 감소시켰 고 $1,000 \mathrm{~Hz}$ 와 $2,000 \mathrm{~Hz}$ 의 이득을 $4 \mathrm{~dB}$ 증가하였다. 3차 조절 은 2 차 조절 10 일 후에 시행하였으며 집 안에서 그릇 부딪히는 소리 또는 물소리 등의 소리가 못 견딜 정도로 크고 거슬린다 고 하여 $4,000 \mathrm{~Hz}$ 이상의 고주파수 이득을 $6 \mathrm{~dB}$ 감소시켰다.

Table 1. Information of selected hearing aid

\begin{tabular}{lc}
\hline \multicolumn{1}{c}{ Side of hearing aid } & Left \\
\hline Number of channels & 24 \\
Hearing aid type & RIC \\
Maximum output / Maximum gain & $119 \mathrm{~dB} / 60 \mathrm{~dB}$ \\
Type of dome & Open $(8 \mathrm{~mm})$ \\
Battery type & $312 \mathrm{~A}$ \\
\hline
\end{tabular}

RIC: receiver in canal

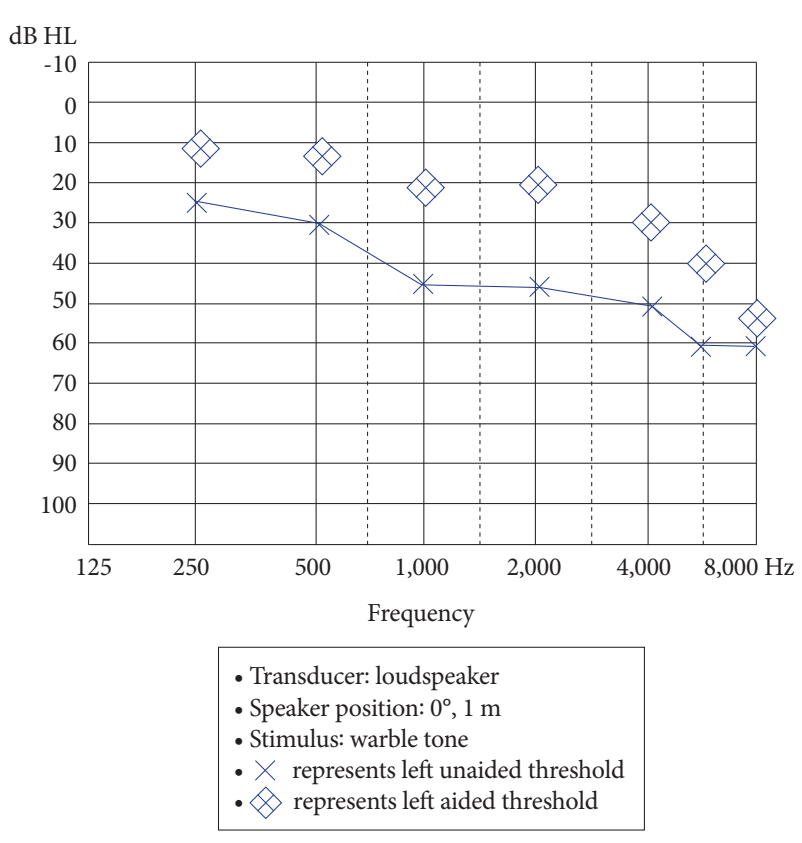

Figure 2. The audiogram showing the differences between aided and unaided thresholds. 
3차의 조절 후 좌측 보청기 착용 유무 상태에서 기능이득을 평가한 결과 $500,1,000,2,000 \mathrm{~Hz}$ 에서는 약 $15 \mathrm{~dB}$ 정도의 이 득을, 나머지 주파수에서 5 10 dB의 이득을 보였다(Figure 2).

\section{사후관리}

3 차 보청기 적합 후 청능훈련을 시행하였고 청능훈련과 보청 기 착용 효과를 측정하기 위해서 청능훈련 전후 어음평가 및 Korean Version of Profile Hearing Aid Benefit (K-PHAB) (Kim et al., 2016)을 사용한 주관적 보청기 이득 평가 결과를 비교하였다. 청능훈련 방법과 어음평가 및 주관적 보청기 이득 평가 결과는 다음과 같다.

\section{RESULTS}

\section{청능훈련}

보청기 착용 후 약 한 달이 지난 후에도 보청기 착용 및 소리 적응에 지속적인 어려움을 호소하여 청능훈련 사례연구 참여 에 동의한 뒤 청능훈련을 시행하였다. 전체 4주 기간 동안 대상 자가 참여 가능한 총 7회의 훈련을 시행하였다. 청능훈련 계획 시 가장 중점을 둔 사안은 직장 내 의사소통 향상으로, 이를 위해 대상자가 근무하는 병원 내 음향 환경과 비슷한 모의 상 황을 센터 내에 재현하였다(Figure 3). 대상자의 경우 충분한 보 청기 적응기간 전에 소음 환경인 근무지에서 보청기를 바로 사 용해야 했기 때문에, 먼저 보청기를 통해 전달되는 상대방과 본
인의 말소리에 대한 빠른 적응을 최우선 목표로 설정하였다. 이 를 위해 청능훈련 도구는 이야기 청능훈련(Kim \& Bahng, 2017)을 사용하였고 다양한 이야기를 듣고 질문에 답하는 형 식으로 진행하였다. 또한 다양한 문장들을 듣고 이해한 뒤 관 련 대화를 나누며 질문에 대답하는 형식으로 전체 7회의 훈련 회기를 진행하였다. 각 회기마다 상담을 통하여 난청에 대한 대 상자의 이해도를 높이고 보청기에 대한 부정적 인식을 개선하 고자 하였다. 대상자의 음향, 사회 심리적 상태에 대한 가족 간 이해 증진과 재활 지원 향상을 위해 마지막 7회 훈련 시 대상자 의 남편과 중학생 자녀를 함께 참여하도록 하였다.

\section{어음평가}

Table 2는 보청기 착용 직후인 청능훈련 전과 7회의 청능훈 련 후 보통 말소리인 $45 \mathrm{~dB}$ HL에서 측정한 WRS와 $\mathrm{SRS}$ 를 비교 한 결과이다. 청능훈련 전과 청능훈련 후 WRS는 $80 \%$ 에서 $88 \%$ 로, SRS는 $85 \%$ 에서 $95 \%$ 로 $10 \%$ 이내의 소폭 상승을 보였다. Figure 2에서 언급한 $64 \%(\mathrm{WRS})$ 와 $72.5 \%(\mathrm{SRS})$ 의 보청기 착용 전과 비교했을 때 보청기의 착용만으로 이미 상당한 어음인지 도의 향상(13 24\%)을 보였고 훈련 후 WRS와 SRS는 각각 $88 \%$ 와 $95 \%$ 로 천장 효과를 보였다.

\section{주관적 만족도 설문지}

보청기 착용 직후인 훈련 전과 훈련 후 $\mathrm{K}-\mathrm{PHAB}$ 설문을 시 행하였다. $\mathrm{K}-\mathrm{PHAB}$ 의 결과는 점수가 낮아질수록 향상된 결과

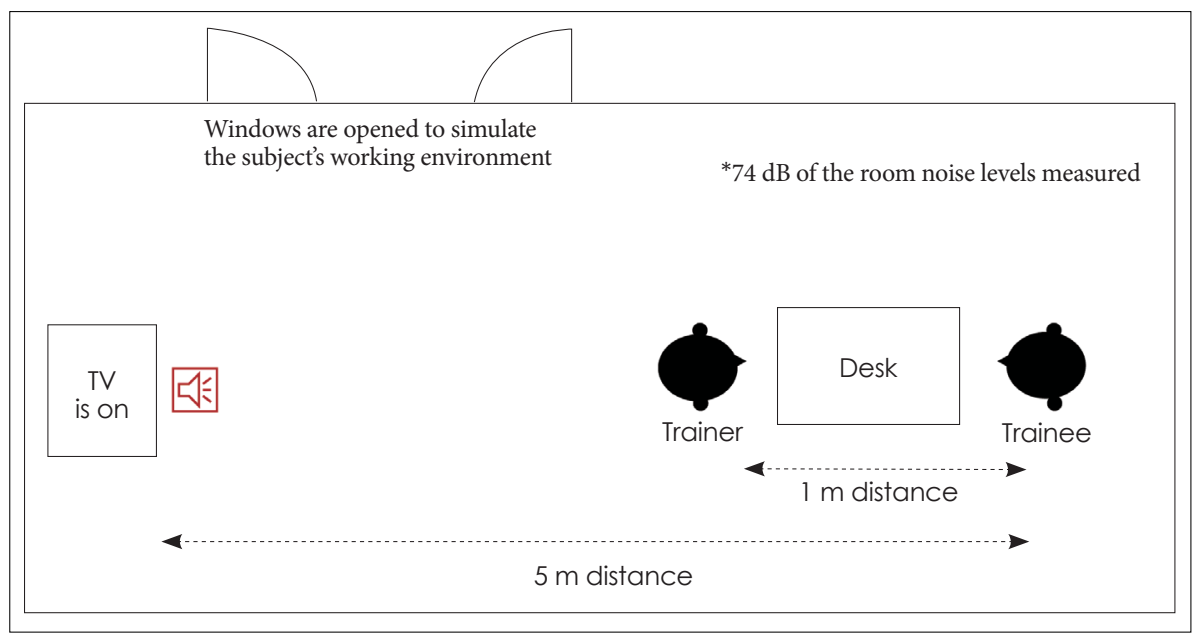

Figure 3. The training room setting simulating the subject's working environment.

Table 2. Comparison of the scores of WRS and SRS between pre- and post- auditory training with hearing aids

\begin{tabular}{ccccc}
\hline Side & \multicolumn{2}{c}{ WRS } & \multicolumn{2}{c}{ SRS } \\
\hline Left & Pre-auditory training (at 45 dB & Post-auditory training (at 45 dB & Pre-auditory training (at 45 dB & Post-auditory training (at 45 dB \\
& HL in front of a loudspeaker) & HL in front of a loudspeaker) & HL in front of a loudspeaker & HL in front of a loudspeaker) \\
& $80 \%$ & $88 \%$ & $85 \%$ & $95 \%$ \\
\hline
\end{tabular}

WRS: word recognition score, SRS: sentence recognition score 


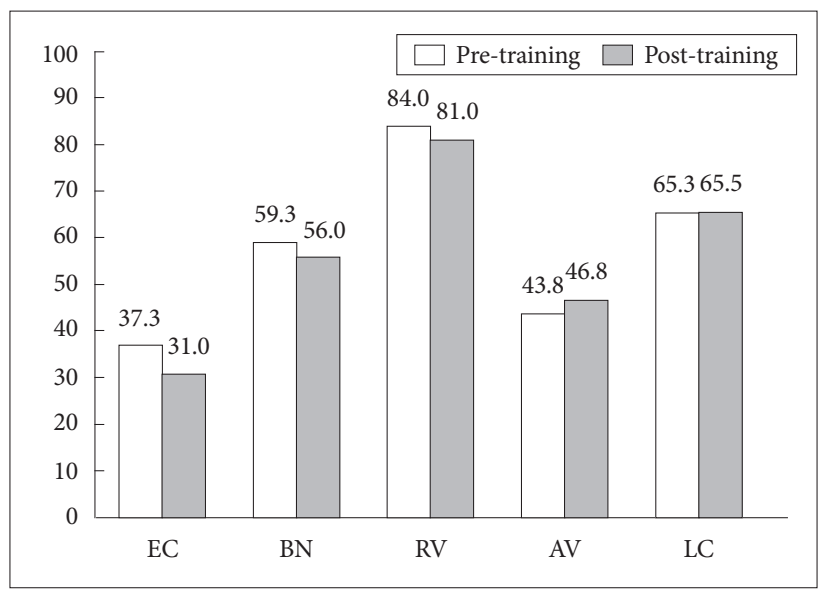

Figure 4. Comparison of the Korean Version of Profile Hearing Aid Benefit questionnaire scores between pre- and post-auditory training. EC: ease of communication, BN: background noise, RV: reverberation, AV: aversiveness, LC: location.

를 보인다. 훈련 전과 후를 비교했을 때 방향성 만족도를 제외하 고 의사소통의 용이성, 소음과 반향음하에서 의사소통의 용이 성 및 날카로운 음향 자극 시 주관적 불편함 항목에서 3 6점의 만족도 증가를 보였다(Figure 4).

\section{기타 주관적 보고}

대상자는 처음에 동료 의사의 권유로 본 센터를 방문하였고 방문 당시 돌발적 청력손실로 인한 충격 및 적응의 어려움, 보 청기 착용에 대한 자발적 참여 및 동기 의식이 부재하였으며 보청기 착용 효과에 대해서도 상당히 부정적인 태도를 가지고 있었다. 보청기 선택에서도 청각적 이득 및 의사소통의 향상보 다는 보청기 크기와 미관상 요인에 주로 중점을 두는 경향을 보였다. 이러한 이유로 청능훈련 초기에는 병원 근무 후에 센터 를 방문하여 피곤함과 훈련에 열심히 참여하지 않는 모습을 보 였으나 훈련이 거듭될수록 훈련에 적극적으로 참여하고 집중 하는 모습을 보였다. 전체 훈련 종료 후 초기의 거부감과 부정 적 인식이 다소 완화되어 보청기 착용에 어느 정도 적응되고 편안한 태도를 보였다. 또한 보청기 착용 후 어음인지도의 향상 정도를 확인하고 보청기 착용 효과에 대한 향상된 신뢰감을 표 현하였으며 자발적 착용 의지를 보였다. 직장 내 의사소통도 보 청기 착용 전보다 향상된 것으로 보고하였다. 가족들이 함께 참여한 마지막 7회차 훈련을 통해 가족들이 대상자의 난청 정 도와 이로 인한 의사소통의 어려움을 이해하는 시간을 가질 수 있었으며 대상자가 보청기를 지속적으로 착용할 수 있도록 가족 차원의 지원과 격려를 강조하였다. 또한 필요 시 센터에서 가족과 함께 소음하 듣기 훈련을 함께 진행하기로 하였다.

\section{DISCUSSIONS}

본 사례는 우측 돌발성 난청으로 심도의 청각손실 발생 뒤 직장 동료의 권유로 센터를 방문하여 좌측에 RIC 보청기를 착 용하고 청능훈련을 시행한 내용을 보고하였다. 보청기 착용 후 청력과 어음인지 정도는 향상되었으나 청능훈련 전후를 비교했 을 때에는 어음인지 정도와 주관적 만족도 측면에서 약간의 향 상만을 보였다. 또한 보청기 착용 후 울림 현상과 관련된 불편 함을 지속적으로 호소하였고, 자칫하면 지속적인 보청기 착용 을 거부하거나 보청기 착용으로 인한 부정적 요인만을 부각하 여 착용 혜택을 감소시킬 수 있는 상황이었다. 이로 인해 상담 초기에는 주로 돌발성 난청으로 인한 충격과 보청기 착용에 대 한 강한 거부감을 보였으나. 이야기와 대화 중심의 청능훈련과 대상자의 필요에 집중한 상담을 통하여 보청기에 대한 전반적 인식 개선, 동기부여, 재활에의 자발적 참여 의지를 높일 수 있 었고 근무 시 보청기의 지속적 착용을 통한 직장 내 의사소통 향상에 기여할 수 있는 발판을 마련하였다.

청능훈련의 효과는 이미 여러 선행연구(Jo et al., 2013; Kim \& Bahng, 2017; Yeo et al., 2014)에서 보고된 바 있다. 타 연구 에 비해 본 사례는 어음인지 정도와 만족도 측면에서 청능훈련 전후 주목할 만한 점수의 증가와 심리, 사회, 태도 등과 관련된 주관적 측면에서 큰 개선은 보이지 않았다. 하지만 본 사례를 통하여 돌발성 난청 환자가 보청기를 통한 재활에 많은 심리적 인 어려움을 가지고 있으며, 이를 청능훈련을 통하여 스스로의 난청과 의사소통의 문제점을 받아들일 수 있는 계기를 가질 수 있다는 것에 의의를 찾을 수 있다. 본 사례를 통하여 돌발성 난 청으로 인한 보청기 사용자의 청능훈련 전략과 관련된 몇 가지 중요한 요인들을 요약하면 다음과 같다:

1) 갑작스런 청각손실로 인한 대상자의 난청 상태에 대한 이 해 증진

2) 청각기기 사용에 대한 자발적 동기 부여와 효과에 대한 이해 증진

3) 사회 심리적 요구에 대한 상담 및 해결 방안 모색

4) 개별화된 청능훈련 환경 및 전략 수립

5) 가족 교육 및 가족 지원 강화

6) 즉각적인 청능훈련 중재

7) 훈련자와의 신뢰감 형성

특히 앞서 언급한 것처럼 돌발성 난청은 진행형 난청보다 청 각손실에 적응할 시간이 짧기 때문에 심리 사회적 측면에서의 적응과 어려움은 그 충격이 좀 더 클 것으로 예측하고 이에 대 한 지원이 강화되어야 할 것으로 본다. 이에 청능훈련은 갑작스 런 난청 상황에 대한 적응과 의사소통 향상을 동시에 향상시킬 수 있는 효과적인 대안으로 적합할 수 있다. 이때 대상자의 사 
회적 활동 또는 가족 지원과 연관된 개별화된 전략과 환경을 구 성하여 상담과 청능훈련을 시행하는 것은 우울감 또는 전반적 정신적 피로 정도를 감소시키고 사회적 의사소통의 어려움을 자각하고 향상시킬 수 있는 방안 모색에도 도움이 될 수 있을 것으로 생각된다. 이외에도 Sekiya et al.(2016)의 연구에서 보 고한 것처럼 풍부한 음향적 요소를 포함하고 있는 음악 청취를 통해 돌발성 난청 후 대뇌피질의 비정상적인 배열과 부적응을 감소시킬 수 있다면, 돌발성 난청 직후 의과적 치료와 함께 또 는 의과적 치료 종료 직후 청능훈련을 통해서 다양한 말 자극 과 음악 등의 음향 자극을 제시하여 청각적 회복을 돕고 추후 보청기나 인공와우 착용을 대비하는 데 효과적일 수 있을 것이 다. 이와 관련하여 앞으로 돌발성 난청으로 인해 청력이 회복되 지 못한 난청인의 청능재활에 대한 좀 더 심도 있는 연구와 방 안이 모색되어야 할 것이다.

본 연구에서는 대상자가 보청기 착용 후 좌측 어음인지검사 에서 보청기 착용 전에도 높은 점수를 보여 보청기 착용 후에 증가 정도가 크지 않았다. 사회 심리적 측면에 대한 요구가 컸음 에도 이를 측정하지 못했다는 한계를 보였다. 후속 연구에서 소 음하 어음검사를 시행하고 사회 심리적 측면의 설문지를 병행 한다면 다각적 측면에서 훈련 효과의 측정, 만족도 향상 및 향 후 재활 계획에 도움이 될 수 있을 것으로 예측되며 이에 대한 보완이 필요할 것으로 생각한다.

중심 단어 : 돌발성 난청·청능훈련·상담.

\section{Acknowledgments}

이 논문은 2015년 대한민국 교육부와 한국연구재단의 지원을 받 아 수행된 연구임(NRF-2015S1A5A8014708). 본 연구에 참여해 주 신 난청인분께 감사드립니다.

\section{REFERENCES}

Chen, J., Liang, J., Ou. J., \& Cai, W. (2013). Mental health in adults with sudden sensorineural hearing loss: An assessment of depressive symptoms and its correlates. Journal of Psychosomatic Research, 75(1), 7274.

Clark, J. G. \& English, K. M. (2014). Emotional responses to hearing loss. In Clark, J. G. \& English, K. M. (1st ed.). Counseling-Infused Audiologic
Care (pp. 27-43). Boston, MA: Pearson.

Health Insurance Review and Assessment Service. (2017, August 25). The number of sudden deaf patients in 2011. ChosunMedia. Retrieved from http://health.chosun.com/site/data/html_dir/2017/08/24/20170824 01733.html.

Jo, Y. Y., Bahng, J., \& Lee, J. H. (2013). Case study of auditory training for an elderly hearing aid user, Audiology, 9(2), 190-194.

Kim, N. K. \& Bahng, J. (2017). Development of a story based auditory training tool and evaluation of the training efficacy for adult hearing impaired listeners. Audiology and Speech Research, 13(2), 133-140.

Kim, T., Sim, S., \& Lee, K. (2016). Development of Korean version of profile of hearing aid benefit. Audiology and Speech Research, 12(4), 209-220.

Korean Agency for Technology and Standards. (2009). Acoustic-Audiometric Test Methods-Part 3: Speech Audiometry, KSI ISO 8253-3. Seoul: Korean Agency for Technology and Standards.

Korean Audiological Society. (2017, September 5). Information of sudden hearing loss. The Korean Audiological Society. Retrieved from http:// www.audiosoc.or.kr/info/?category=20.

Lee, J. H., Lee, S. G., \& Bahng, J. (2016). Case study of auditory training for long-term users of hearing aids with poor word recognition. Audiology and Speech Research, 12(3), 190-194.

Lee, J. I., Bahng, J., \& Lee, J. H. (2017). Development and verification of auditory training tool for children. Audiology and Speech Research, 13(2), 123-132.

Lin, C. S., Lin, Y. S., Liu, C. F., Weng, S. F., Lin, C., \& Lin, B. S. (2016). Increased risk of sudden sensorineural hearing loss in patients with depressive disorders: Population-based cohort study. The Journal of Laryngology and Otology, 130(1), 42-49.

Schreiber, B. E., Agrup, C., Haskard, D. O., \& Luxon, L. M. (2010). Sudden sensorineural hearing loss. Lancet, 375(9721), 1203-1211.

Sekiya, K., Fukushima, M., Teismann, H., Lagemann, L., Kakigi, R., Pantev, C., et al. (2016). Neuro-rehabilitation approach for sudden sensorineural hearing loss. Journal of Visualized Experiments, 107, e53264.

Stachler, R. J., Chandrasekhar, S. S., Archer, S. M., Rosenfeld, R. M., Schwartz, S. R., Barrs, D. M., et al. (2012). Clinical practice guideline: Sudden hearing loss. Otolaryngology-Head and Neck Surgery, 146(3 Suppl), S1-S35.

Sweetow, R. W. \& Sabes, J. H. (2010). Auditory training and challenges associated with participation and compliance. Journal of the American Academy of Audiology, 21(9), 586-593.

Tseng, C. C., Hu, L. Y., Liu, M. E., Yang, A. C., Shen, C. C., \& Tsai, S. J. (2016). Risk of depressive disorders following sudden sensorineural hearing loss: A nationwide population-based retrospective cohort study. Journal of Affective Disorders, 197, 94-99.

Tye-Murray, N. (2009). Counseling, psychosocial support, and assertiveness training. In Tye-Murray, N. (3rd ed.). Foundations of Aural Rehabilitation: Children, Adults, and Their Family Members (pp. 349-382). Clifton Park, NY: Delmar Cengage Learning.

Yeo, S. H., Bahng, J. H., \& Lee, J. H. (2014). Efficacy of auditory training using sentences in noise for hearing aid users. Audiology, 10(1), 65-75. 